\title{
HUMAN ADJUVANT DISEASE SECONDARY TO FOREIGN SUBSTANCE INJECTIONS AS A CAUSE OF SECONDARY LOWER EXTREMITY LYMPHEDEMA
}

\author{
J. López-Mendoza, L.M. Alvarado-Fernández
}

Department of Plastic and Reconstructive Surgery (JL-M), Hospital Angeles del Pedregal, Mexico City, and Department of Plastic and Reconstructive Surgery (LMA-F), Centro Médico ISSEMYM, Toluca, Estado de México, Mexico

\section{ABSTRACT}

Non-FDA approved foreign substances injected in areas such as the hips and buttocks for aesthetic purposes have resulted in significant complications including secondary lymphedema. We sought to demonstrate lymphoscintigraphic abnormalities in a group of patients with lower extremity edema following infiltration of foreign substances in but-tocks and hips to confirm secondary lymphedema. This retrospective and observational study examined 10 lower extremities for lymphoscintigraphic abnormalities from patients with history of infiltration of foreign substances and subsequent complaints about lower extremity edema. Clinical evaluation, lymphedema index, lymphoscintigraphy, and Transport Index (TI) were evaluated. The average lymphedema index documented in each limb was 236.45 categorizing most of our patients in a lower limb lymphedema stage I. The average TI was 15.7 points (8.6 - 22.8 points) demonstrating that all patients show abnormal lymphoscintigraphy (LSG) patterns. LSG findings confirm the diagnosis of lower extremity lymphedema secondary to injection of foreign substances in the buttocks and hips in the group of patients studied.

Keywords: lymphedema, lymphoscintigraphy, lymphadenopathy, Human Adjuvant Disease, foreign bodies, xenobiotics, silicone, polymers

Human adjuvant disease (HAD) was described in 1964 by Miyoshi as an immunological mediated disorder caused by exposure to foreign substances that act as adjuvants $(1,2)$. These substances include mainly paraffin oil, mineral oil, and silicon and are used for cosmetic purposes (3). Immediate aesthetic results, low cost, and its painless instillation have encouraged its rapid use (4). It is important to clarify that the term filler is commonly used among plastic surgeons for FDA-approved substances. Our series of patients received non-approved substances for cosmetic purposes and by non-health professionals.

Cabral reported an association between the injection of modelants (foreign non-approved substances) and the development of autoimmune disease (human adjuvant disease). His results implicate IL-1 in the amplification of the disease process (5).

Multiple complications have been seen with the use of these substances ranging from local problems such as deformity at the site of injection, granulomas and skin changes, to systemic manifestations, such as: ASIA syndrome (autoimmune/inflammatory syndrome induced by adjuvants), pneumonitis, massive systemic embolism, migration of modeling 
substances by gravity, and secondary lymphedema, sporadically reported in the literature, but never documented with imaging studies $(6,7)$. Potential etiologies include lymphadenopathy (migration to regional lymph nodes), extrinsic compression of lymph vessels, or even lymph vessel damage with none of these having been examined (7).

Several papers have reported the association between human adjuvant disease and lymphedema. Dominguez Zambrano reported lymphedema as a complication after reviewing 177 patients with history of injection of different substances: vegetable, animal, mineral oils and polymethylmethacrylate. No percentages or rates were reported, and they only mention lymphedema as a possible complication (7). Gaber reported a case of secondary lymphedema due numerous foreign-body granulomas producing inguinal lymphadenopathy and external lymphatic compression secondary to silicone injection of the hips and buttocks (8). Morgenstern reported regional lymphadenopathy, with or without infiltration of adjacent soft tissue. Compression of surrounding organs have also been recognized as long-term complications of oil injections (9). Two patients from Cabral series died, in one, silicon-like modelants could be identified in an inguinal lymph node during her post-mortem studies; she had been injected in the buttocks (5). Other authors have found patients with silicone particles in the synovial membrane and in axillary lymph nodes after metacarpophalangeal joint replacement. Microscopically, silicone particles in synovium and lymph node were identical to particles abraded from a new prosthesis (10).

Lymphedema is a chronic, underdiagnosed disease of the lymphatic system which can cause severe disabling edema of the lower limbs. Lymphoscintigraphy (LSG) is the gold standard for the evaluation of lymphatic system function. It is a minimally invasive technique in which radionuclides are used to evaluate the regional lymphatic drainage system. It provides information about lymphatic transport and filtration. After intradermal injection of a radioactive tracer, images of the extremities are made at different time inter- vals $(15,30,60$ and 120 minutes), which serve to provide quantitative and qualitative analysis of the lymphatic system (11). This diagnostic study is useful in the identification and management of patients with lymphedema, to confirm diagnosis, evaluate the severity of lymphedema, and may be used to conduct a follow-up of the response to treatment (12).

Magnetic resonance imaging (MRI), contrast enhanced magnetic resonance lymphangiography (CEMRL), and indocyanine green (ICG) lymphography are alternative imaging modalities for the lymphatic system with advantages and disadvantages but LSG is inexpensive and more available driving selection of LSG for lymphatic imaging for our patients $(13,14)$.

\section{MATERIAL AND METHODS}

This study was a single-center retrospective and observational case series. We included 10 lower extremities from 5 patients with history of foreign substances injection in the buttocks and hips. Patients were collected from January 2016 to January 2019 and all presented lower extremities edema. We reviewed medical records, which included clinical assessment of lymphedema, lymphedema index, and LSG of bilateral lower extremities. Collected demographic and clinical data included patient's sex, age, time since the application, and substance applied. The study was planned following the Declaration of Helsinki of 1964 and the revision of 2008 and was ap-proved by the ethics of human investigation committee of Universidad Autónoma del Estado de México. All patients agreed and al-lowed the authors to publish their case details and images signing a publication consent form.

The lower extremity lymphedema index was calculated using circumferences and BMI; a summation of squared circumfer-ences was divided by BMI obtained from physical examinations (Fig. 1). We used the lower extremity lymphedema index as Yama-moto described: LEL index $<250$ correspond-ed to LEL stage I, 250 to 300 corresponded to LEL stage II, 300 to 350 corresponded to LEL stage III, and > 350 corresponded to LEL 


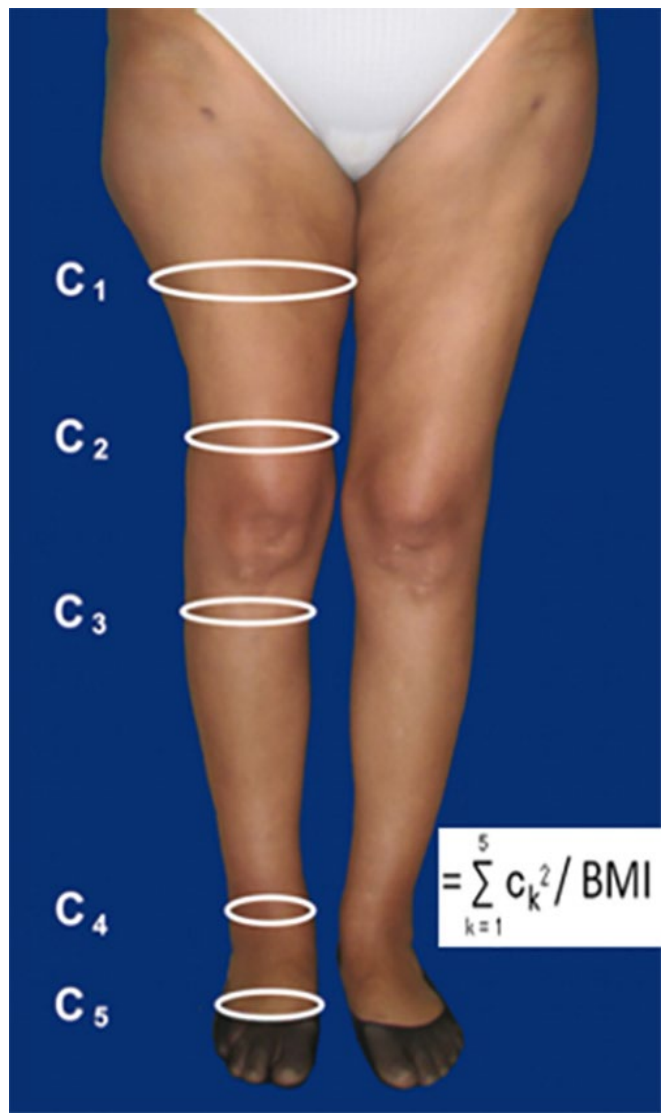

Fig. 1. Location of the 5 circumferences and the formula (insert) used to calculate the lower leg lymphedema index.

stage IV (15).

LSG was performed and evaluated by a single nuclear medicine specialist through subcutaneous injection of the nanocolloid Technetium $99 \mathrm{~m}$. Static images were obtained at 15, 30, 60 and 120 minutes after injection. The following parameters were considered to obtain the transport index in each pelvic limb: transport kinetics, distribution pattern, index time for the appearance of regional lymph nodes, number and collection of colloids in lymph nodes, and presence and quality of the colloid uptake by the lymphatic vessels. Summation of these five components resulted in the transport index, which could range from 0 to 45 points. Values less than 5 means a normal study with higher scores representing ab-

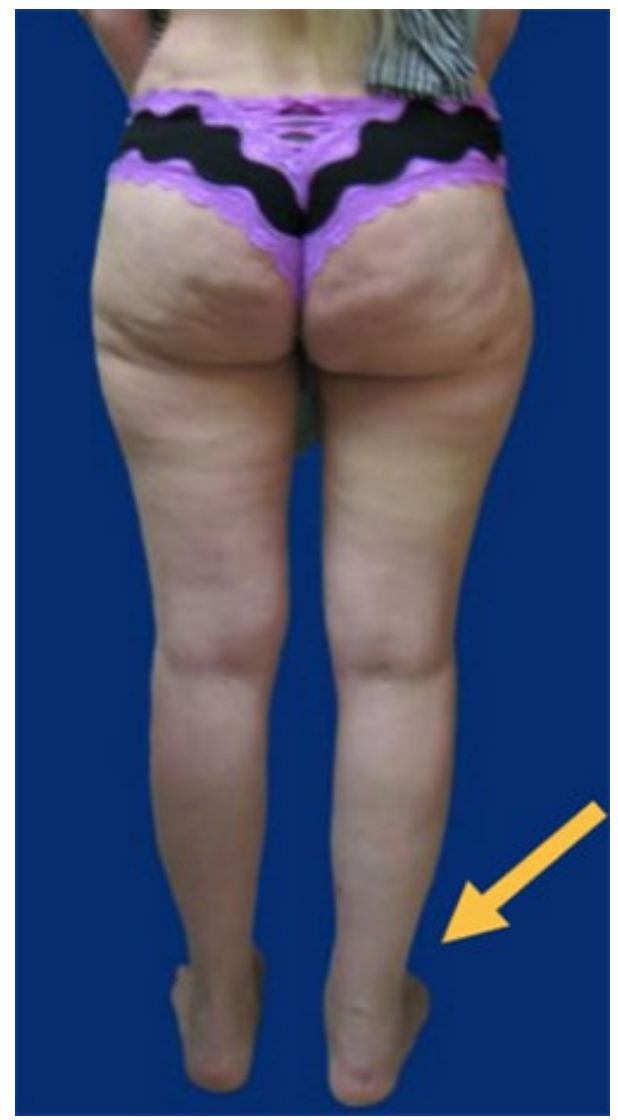

Fig. 2. Clinical presentation of lower extremity edema. In this subject, the area around the ankle (arrow) was the main complaint.

normal or pathological results. In addition, the abnormal presence of accessory lymph vessels and popliteal lymph nodes were assessed and reported as abnormal findings $(9,16-20)$.

\section{RESULTS}

All patients in the study were women averaging 49.4 years in age (range 32-66 years). The average time since the application of foreign substance was 6.6 years. None of the patients knew which foreign substance was used (Table 1). Patients mainly experienced skin hyperpigmentation ( $100 \%$ of patients), chronic fatigue $(80 \%)$, skin stiffness $(60 \%)$, and pain (40\%) (Table 2).

The lymphedema index averaged 236.45 


\begin{tabular}{|l|l|l|l|l|l|l|l|l|}
\hline \multicolumn{7}{|c|}{ Demographic Information of Study Sulbjects } \\
\hline Subject & AGE & Gender & BMI & $\begin{array}{l}\text { Edema } \\
\text { onset } \\
\text { (years) }\end{array}$ & Product & $\begin{array}{l}\text { Injection } \\
\text { site }\end{array}$ & $\begin{array}{l}\text { Who } \\
\text { applied } \\
\text { it? }\end{array}$ & COMORBIDITIES \\
\hline 1 & 32 & F & 25.3 & 8 & Unknown & $\begin{array}{l}\text { Gluteal } \\
\text { and hip }\end{array}$ & $\begin{array}{l}\text { Cosmeto- } \\
\text { logist }\end{array}$ & None \\
\hline 2 & 36 & F & 22.2 & 6 & Unknown & $\begin{array}{l}\text { Gluteal } \\
\text { and hip }\end{array}$ & $\begin{array}{l}\text { Gym } \\
\text { instructor }\end{array}$ & None \\
\hline 3 & 57 & F & 29.3 & 4 & Unknown & $\begin{array}{l}\text { Gluteal } \\
\text { and nose }\end{array}$ & $\begin{array}{l}\text { Cosmeto- } \\
\text { logist }\end{array}$ & $\begin{array}{l}\text { Hipothyroidism, } \\
\text { Tonsillectomy, } \\
\text { Ooforectomy }\end{array}$ \\
\hline 4 & 56 & F & 27.6 & 7 & Unknown & $\begin{array}{l}\text { Gluteal } \\
\text { and nose }\end{array}$ & Friend & None \\
\hline 5 & 66 & F & 30.8 & 8 & Unknown & $\begin{array}{l}\text { Gluteal } \\
\text { and hip }\end{array}$ & Unknown & $\begin{array}{l}\text { Diabetes Mellitus 2, } \\
\text { Carpal tunnel } \\
\text { syndrome, spine } \\
\text { surgery }\end{array}$ \\
\hline AVG & 49.4 & F & 27.04 & 6.6 & Unknown & & \\
\hline
\end{tabular}

\section{TABLE 2}

\section{Clinical Presentation of Features in Study Subjects}

\begin{tabular}{|l|c|c|c|c|c|}
\hline \multicolumn{7}{|c|}{$\begin{array}{c}\text { Nubject } \\
\text { Number }\end{array}$} \\
\hline Feature & 1 & 2 & 3 & 4 & 5 \\
\hline PAIN & $\mathrm{y}$ & $\mathrm{n}$ & $\mathrm{y}$ & $\mathrm{n}$ & $\mathrm{y}$ \\
\hline SKIN STIFFNESS & $\mathrm{n}$ & $\mathrm{n}$ & $\mathrm{n}$ & $\mathrm{y}$ & $\mathrm{y}$ \\
\hline FEVER & $\mathrm{n}$ & $\mathrm{n}$ & $\mathrm{n}$ & $\mathrm{n}$ & $\mathrm{n}$ \\
\hline CHRONIC FATIGUE & $\mathrm{y}$ & $\mathrm{n}$ & $\mathrm{y}$ & $\mathrm{y}$ & $\mathrm{y}$ \\
\hline HYPERPIGMENTATION & $\mathrm{y}$ & $\mathrm{y}$ & $\mathrm{y}$ & $\mathrm{y}$ & $\mathrm{y}$ \\
\hline ULCERS & $\mathrm{n}$ & $\mathrm{n}$ & $\mathrm{n}$ & $\mathrm{n}$ & $\mathrm{n}$ \\
\hline MEDICAL TREATMENT & $\mathrm{y}$ (betametasone) & $\mathrm{n}$ & $\mathrm{n}$ & $\mathrm{n}$ & $\mathrm{n}$ \\
\hline
\end{tabular}

$\mathrm{n}=\mathrm{no}, \mathrm{y}=$ yes 


\begin{tabular}{|c|c|c|c|c|c|c|c|c|}
\hline \multicolumn{9}{|c|}{$\begin{array}{l}\text { TABLE } 3 \\
\text { BMI and Imaging Results for Study Subjects }\end{array}$} \\
\hline Subject & BMI & $\begin{array}{l}\text { LE } \\
\text { INDEX }\end{array}$ & Stage & $\begin{array}{l}\text { Transport } \\
\text { index }\end{array}$ & $\begin{array}{c}\text { Time to } \\
\text { node } \\
\text { (minutes) }\end{array}$ & $\begin{array}{c}\text { Lymph } \\
\text { node } \\
\text { uptake }\end{array}$ & $\begin{array}{c}\text { Dermal } \\
\text { backflow }\end{array}$ & $\begin{array}{l}\text { Popliteal } \\
\text { node }\end{array}$ \\
\hline 1 & 25.3 & 200.17 & 1 & 21.2 & 30 & reduced & 0 & + \\
\hline 2 & 25.3 & 204.8 & 1 & 9 & 15 & reduced & 0 & + \\
\hline 3 & 22.2 & 245.05 & 1 & 10 & 15 & normal & 0 & - \\
\hline 4 & 22.2 & 252.21 & 2 & 22.8 & 120 & reduced & 0 & - \\
\hline 5 & 29.3 & 259.15 & 2 & 14.6 & 15 & reduced & 0 & - \\
\hline 6 & 29.3 & 254.16 & 2 & 8.6 & 15 & normal & 0 & - \\
\hline 7 & 24.4 & 228.04 & 1 & 20.6 & 15 & reduced & 0 & + \\
\hline 8 & 24.4 & 236.16 & 1 & 14.6 & 15 & reduced & 0 & + \\
\hline 9 & 23.4 & 236.43 & 1 & 13.6 & 15 & reduced & 0 & + \\
\hline 10 & 23.4 & 248.34 & 1 & 22 & 30 & absent & 0 & - \\
\hline
\end{tabular}
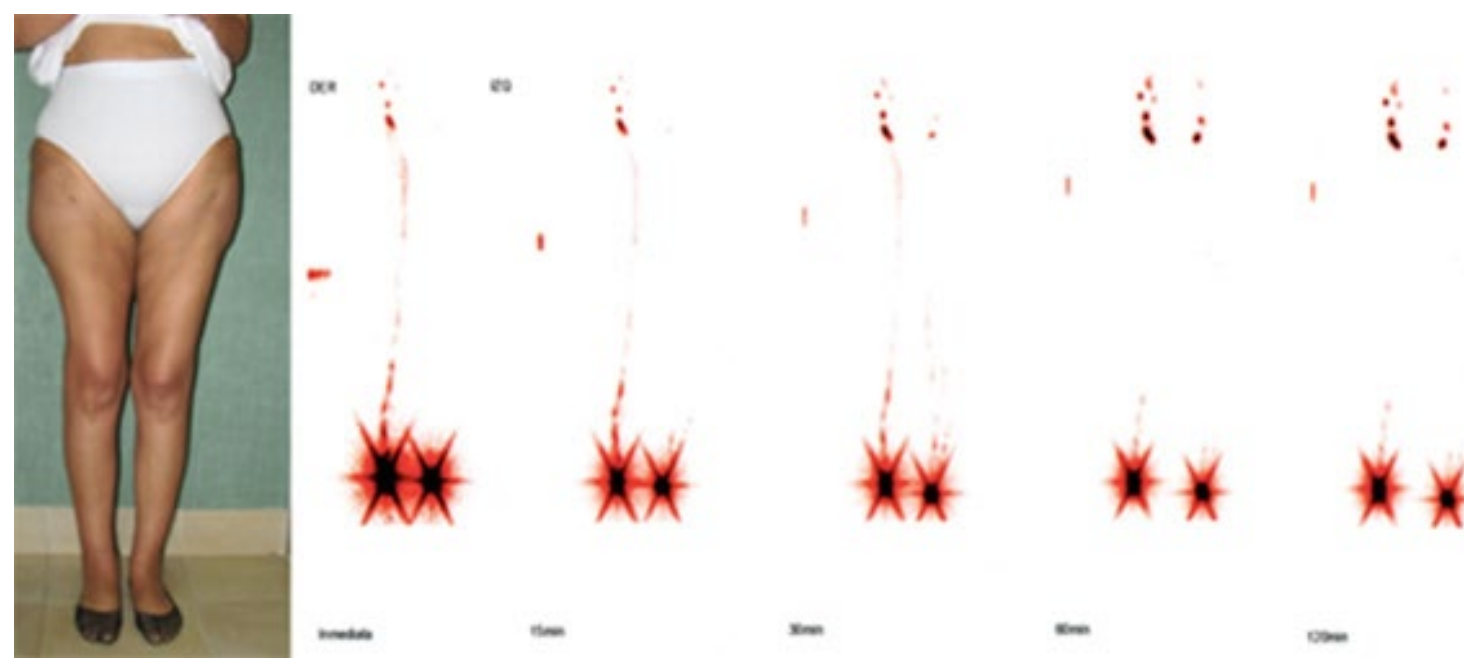

Fig. 3. Subject photograph displaying subclinical lymphedema with the associated changes in LCG images including asymmetric uptake in the lymph nodes and asymmetric lymph vessels on the left. 
(range 200.17 - 259.15) corresponding to 7 extremities at stage I LEL and 3 at stage II LEL (Fig. 2).

The average TI was 15.7 points, with a range of $8.6-22.8( \pm 5.57)$ demonstrating that all LSG examinations reported abnormal patterns ( Table 3).

The presence of collateral lymphatic vessels was found in six lower extremities and popliteal lymph nodes were also found in five lower limbs. The presence of lymphocele was observed in one lower extremity LSG, although the patient did not report any clinical manifestation (Fig. 3).

\section{DISCUSSION}

The frequency of secondary lymphedema is between $10 \%$ - $49 \%$ (20). Even mild lymphedema of the lower limbs can produce discomfort and chronic problems with walking, running, and limitation in the use of shoes.

This lymphatic dysfunction results in decreased transport of lymphatic fluid, producing the clinical picture of lymphedema. Dysfunction by either failure of lymphatic vessel dilatation by extrinsic compression or impairment of the intrinsic activity of the lymphatic valves by fibrosis, stenosis, or incompetence have all been reported (17).

LSG is a very important tool for the adequate and early diagnosis of the lymphatic system compromise due to diverse causes. The transport index is a calculation performed with LSG findings and assess the lymphatic circulation providing data on the lymphatic system function. Confirmation of lymphedema due to lymphatic insufficiency is useful to exclude other causes of limb swelling and to initiate appropriate treatment $(21,22)$.

In this study, we observed abnormal patterns in the lymphatic system function of different grades in each patient. Although clinically $70 \%$ of the patients had a lower extremity lymphedema index that placed them in lymphedema stage I, all the LSG studies yielded abnormal patterns, which indicates that all patients with a history of injection of foreign substances, human adjuvant disease and concomitant lower extremity volume augmentation had lymphedema.

We concluded this because lymphadenopathy as a cause of foreign substances injection has been described in other reports and hypothesize that a blockage of the lymph node likely occurred and this initiated the lymphedema.

Stewart et al. reported that the sensitivity of LSG in diagnosing lymphedema was $\mathbf{9 7 \%}$ and its specificity $100 \%$, and it clearly differentiated between lymphedema and venous edema. He reported an increased uptake in the ilio-inguinal nodes of patients with venous edema as compared with normal limbs and this was not seen in our series (21).

Although circumference measurement is common and useful for documenting lower extremity lymphedema by comparison with the unaffected extremity in unilateral cases, it has several disadvantages. First, comparing different cases is not possible due to variability of individuals. Second, in patients with bilateral lower extremity lymphedema, comparison with the unaffected side cannot be made.

The LEL index correlates well with the conventional clinical stages and can be useful in determining the severity of a condition or efficacy of treatment, enabling evaluation regardless of the body type by means of absolute values (23).

Volume measurement is one of the most commonly used methods for LEL evaluation because of its objectivity. However, volume comparison between different patients with different body types may be inappropriate because body-type difference seems to significantly affect leg volume (LV). The LEL index was calculated using circumferences and body mass index (BMI), and LV was calculated using a summed truncated cone model. The LEL index and LV/BMI ratio stayed constant regardless of BMI, whereas LV significantly increased with increase in BMI. With simplicity of calculation, the LEL index allows more practical body-type-corrected LV evaluation compared with volumetry-based evaluations (24).

Perometry, measures the overall limb volume including muscle and fat but not specifically our area of interest in early lym- 
phedema diagnosis-extracellular fluid (ECF). Therefore, perometry in early lymphedema could fail to measure changes in fluid volume, and also does not account for changes in BMI (25).

For Cambria et al, the TI with a value of 5 as a cut-off point between normal and abnormal (lymphedema), has specificity of $94 \%$ and sensitivity was $80 \%(17,21)$. Our patients were all beyond this cut-off point confirming some degree of lymphedema. Kleinhans, who described the classic TI, used TI $=10$ to discriminate between normal and pathological lymph drainage, in the classic study sensitivity was $97.4 \%$ and specificity $90.3 \%$ (26).

A point for discussion could be a nondiagnosed primary lymphedema, but due the age of patients (49.4 year-old average) this seems unlikely. In addition, none of the patients experienced any edema symptoms before injection of the foreign substances. Also, the appearance at an average 6.6 years after injection corresponds with previous papers about the onset of complications after injection of foreign substances. None of the patients had familiar history of congenital lymphedema and LSG findings also do not correspond with primary lymphedema classic findings including Cambria et al's data that showed higher scores for primary lymphedema (17). According to Cambria et al's report, patients with lymphedema (primary or secondary) had a higher TI than patients with other causes for limb swelling. The TI, and all but one of its components tended to be higher among the patients with primary lymphedema as compared with those with secondary lymphedema. In our series TI were lower than his cut-off value for primary lymphedema.

LSG is the gold standard imaging method to diagnose lymphedema and provides information regarding both lymphatic anatomy as well as lymphatic function. Two other imaging modalities for lymphatic analysis are indocianine green lymphograpghy (ICG) and magnetic resonance lymphography (MRL). These can be used in combination with LSG or alone for specific purposes. ICG is a safe, minimally invasive, and useful tool for the presurgical evaluation of extremity lymphedema.
Imaging is performed by injecting ICG into the interdigital web spaces and fluorescence images of lymphatic vessels can be obtained with a near-infrared camera device. The fluorescence images are digitalized for real-time display. Characteristic indocyanine green lymphography patterns are consistent and correlate with clinical severity. Yamamoto showed mild cases of lymphedema characterized by a linear lymphatic channel pattern. In more severe cases, lymphatic channels demonstrated dermal backflow pattern (27). The main limits are the time after injection needed to mark the lymphatic vessels and difficulty to clearly identify lymphatic vessels course in late-stage lymphedema. In addition, ICG has a limited penetration depth of approximately $2 \mathrm{~cm}$ presenting another disadvantage (28). Finally, is not available at our center.

MRL is a non invasive imaging modality capable of providing high- resolution 3D images of the lower extremities to define the severity and extent of lymphedema and depict individual lymphatic channels (29). MRI offers greater detail of lymphatic architecture, without the radiation exposure, and has been shown to be equally sensitive and specific for the diagnosis of lymphedema (30). Currently, MRL is used for preoperative planning to better individualize treatment and to confirm the diagnosis in equivocal cases. A main disadvantage is potential venous contamination after intracutaneous injection of the contrast agent (29). LSG is a cheap and accessible study for our patients, that was another reason we chose this method.

Further studies are needed to determine the exact mechanism of damage to lymphatic drainage. Definitely, the best way to assess the architecture of regional nodes is by histopathological evaluation $(5,9,10)$. Because of the risk of worsening the lymphedema, we did not take samples of the regional nodes. Further clinical trials with patient's authorization should be able to assess the underlying pathogenesis of this disease.

Based on our findings and analysis, we can infer that these foreign substances exert their deleterious effect in part through compromise in the lymphatic transport leading to 
accumulation of the lymphatic fluid in lower extremities. Among the theories formulated, we speculate that this alteration may be due to extrinsic compression by the foreign substance directly, and/or migration of the modeling substance to lymph nodes causing their obstruction.

\section{CONCLUSIONS}

This study demonstrates the emergence of lower extremity lymphedema due to the injection of foreign substances in the buttocks and hips. With the help of the nuclear lymphoscintigraphy, it was possible to confirm the diagnosis of secondary lymphedema.

Despite growing interest on human adjuvant disease complications, there is a lack of published studies on this matter. Thus, more and larger studies are needed to explore the pathogenesis and determine optimal treatment of secondary lymphedema due to human adjuvant disease.

\section{AKNOWLEDGMENT}

The authors would like to acknowledge Claudia Herrera Ayala, MD from the Department of Nuclear Medicine, Oncological Center, ISSEMYM Estado de México for her invaluable help in analyzing the lymphoscintigraphies of all patients.

\section{CONFLICT OF INTEREST AND DISCLOSURE}

The authors declare no competing financial interests exist.

\section{REFERENCES}

1. Miyoshi, K, T Miyamura, Y Kobayashi: Hypergammaglobulinemia by prolonged adjuvanticity in men: Disorders developed after augmentation mammoplasty. J. Keio Med. Soc. 2122 (1964), 9-14.

2. Baldwin Curtis, M Jr, EN Kaplan: Siliconeinduced human adjuvant disease? Ann. Plast. Surg. 10 (1983), 270-273.

3. Cárdenas-Camarena, L: Managing the mammary gland infiltrated with foreign substances: Different surgical alternatives. Ann. Plast, Surg. 62 (2009), 621-626.

4. Ahmed, U, A Freeman, A Kirkham, et al: Self injection of foreign materials into the penis. Ann. R. Coll. Surg. Engl. 99 (2017), e78-e82.

5. Cabral, A, J Alcocer-Varela J, R OrozcoTopete, et al: Clinical, histopathological, immunological and fibroblast studies in $\mathbf{3 0}$ patients with subcutaneous injections of modelants including silicone and mineral oils. Rev. Invest. Clin. 46 (1994), 257-266.

6. Torres Gómez, B, G Medrano Ramírez, R Priego Blancas, et al: Enfermedad por la infiltración de sustancias modelantes con fines estéticos. Cir. Plast. 20 (2010), 124-132.

7. Dominguez-Zambrano, A, J Haddad-Tame, I Torres-Baltazar, et al: Enfermedad por modelantes: problemática actual en México y presentación de casos. Cir. Plást. Iberolatinoam. 39 (2013), 399-405.

8. Gaber, Y: Secondary Lymphoedema of the lower leg as an unusual side-effect of a liquid silicone injection in the hips and buttocks. Dermatology 208 (2004), 342-344.

9. Morgenstern, L, SH Gleischman, SL Michel, et al: Relation of free silicone to human breast carcinoma. Arch. Surg. 120 (1985), 573.

10. Christie, AJ, KA Weinberger, M Dietrich: Silicone lymphadenopathy and synovitis complications of silicone elastomer finger joint prostheses. JAMA 237 (1977), 14631464.

11. Sadegui, R, G Kazemzadh, M Keshtgar: Diagnostic application of lymphoscintigraphy in the management of lymphedema. Hellenic J. Nucl. Med. 13 (2010), 6-10.

12. Hage, J, R Kanhai, A Oen, et al: The devastating outcome of massive subcutaneous injection of highly viscous fluids in male-tofemale transsexuals. Plas. Recon. Surg. 107 (2001), 734-741.

13. Warren, A, H Brorson, L Borud L, S Slavin: Lymphedema. A comprehensive review. Ann. Plast. Surg. 59 (2007), 464-472.

14. Cellina, M, G Oliva, A Menozzi, et al: Noncontrast magnetic resonance lymphangiography: An emerging technique for the study of lymphedema. Clin. Imag. 10 (2018), 006.

15. Yamamoto, $\mathrm{T}, \mathrm{N}$ Matsuda, $\mathrm{T}$ Todokoro, et al: Lower extremity lymphedema index a simple method for severity evaluation of lower extremity lymphedema. Ann. Plas. Surg. 67 (2011), 637-640.

16. Suga, K, N Kume, N Matsunaga, et al: 
Assessment of leg oedema by dynamic lymphoscintigraphy with intradermal injection of technetium-99m human serum albumin and load produced by standing. Eur. J. Nucl. Med. 28 (2001), 294-303.

17. Cambria, RA, P Gloviczki, JM Naessens, HW Wahner: Noninvasive evaluation of the lymphatic system with lymphoscintigraphy: A prospective, semi quantitative analysis in 386 extremities. J. Vas. Surg. 18 (1993), 773782.

18. Kalawat, TC, RK Chittoria, PK Reddy, et al: Role of lymphoscintigraphy in diagnosis and management of patients with leg swelling of unclear etiology. Indian J. Nucl. Med. 27 (2012), 226-230.

19. Villa G, C Campisi, M Ryan, et al: Procedural recommendations 1 for lymphoscintigraphy in the diagnosis of peripheral lymphedema: the Genoa protocol. Nucl. Med. Imaging 53 (2019), 47-56.

20. Szuba, A, W Shin, W Strauss, S Rockson: The third circulation: radionuclide lymphoscintigraphy in the evaluation of lymphedema. J. Nucl. Med. 44 (2003), 43-57.

21. Stewart, G, J Gaunt, DN Croft, NL Browse: Isotope lyphography: A new method of investigating the role of the lymphatics in chronic limb oedema. Br. J. Surg. 72 (1985), 906-909.

22. Kalawat, TC, RK Chittoria, PK Reddy, et al: Role of lymphoscintigraphy in diagnosis and management of patients with leg swelling of unclear etiology. Indian J. Nucl. Med. 27 (2012), 226-230.

23. Weissleder, H., R Weissleder: Lymphedema: Evaluation of qualitative and quantitative lymphoscintigraphy in 238 patients. Radiology. 167 (1988), 729-735.

24. Yamamoto, T, N Yamamoto, N Hayashi, et al: Practicality of the lower extremity lymphedema index: Lymphedema index versus volumetry-based evaluations for bodytype-corrected lower extremity volume evaluation. Ann. Plast. Surg. 77 (2016), 115118.
25. Dylke, E, L Ward, SH Kilbreath: Standardized approach to lymphedema screening. Oncologist 18 (2013), 1242.

26. Kleinhans, E, RG Baumeister, D Hahn, et a: Evaluation of transport kinetics in lymphoscintigraphy: Follow-up study in patients with transplanted lymphatic vessels. Eur. J. Nucl. Med. 10 (1985), 349-352.

27. Yamamoto, T, M Narushima, K Doi, et al: Characteristic indocyanine green lymphography findings in lower extremity lymphedema: The generation of a novel lymphedema severity staging system using dermal backflow patterns. Plast. Reconstr. Surg. 127 (2011), 1979-1986.

28. Cellina, M, G Oliva, A Menozzi, et al: Noncontrast magnetic resonance lymphangiography: An emerging technique for the study of lymphedema. Clin. Imaging 53 (2019), 126-133.

29. Mitsumori, L, E McDonald, P Neligan, J Maki: Peripheral magnetic resonance lymphangiography: Techniques and applications. Tech. Vasc. Interv. Radiol. 19 (2016), 262-272.

30. Warren, A, H Brorson, L Borud, S Slavin: Lymphedema. A comprehensive review. Ann. Plast. Surg. 59 (2007), 464-472.

\author{
Javier Lopez Mendoza, MD, MBA, FACS \\ Hospital Angeles del Pedregal \\ Camino a Santa Teresa 1055. Office 605. \\ Col. Heroes de Padierna. Del. Magdalena \\ Contreras \\ Mexico City, MEXICO \\ E-mail lopezmendozamd@gmail.com \\ Telephone $\mathbf{+ 5 2 5 5 5 1 3 5 4 2 8 5}$
}

